\title{
Erratum to: Influence of different GPS receiver antenna calibration models on geodetic positioning
}

\author{
Q. Baire · C. Bruyninx $\cdot$ J. Legrand \\ E. Pottiaux $\cdot$ W. Aerts $\cdot$ P. Defraigne $\cdot$ \\ N. Bergeot $\cdot$ J. M. Chevalier
}

Published online: 14 May 2015

(C) Springer-Verlag Berlin Heidelberg 2015

\section{Erratum to: GPS Solut (2014) 18:529-539 \\ DOI 10.1007/s10291-013-0349-1}

In the original publication, the last five sentences of the third paragraph under the section Results were incorrectly published. The corrected text is given below.

"Specifically the update of the type mean robot calibration of the TRM29659.00/NONE caused a position offset of $-3.9 \mathrm{~mm}$ in the east component and $5.8 \mathrm{~mm}$ in the up component. Note that its type mean calibration in the igs08.atx is based on 18 individual calibrations compared to 12 in the igs05.atx, hence the importance of including RMS values in the IGS antenna calibration files."

The online version of the original article can be found under doi:10.1007/s10291-013-0349-1.

Q. Baire $(\bowtie) \cdot$ C. Bruyninx · J. Legrand · E. Pottiaux · W. Aerts · P. Defraigne - N. Bergeot - J. M. Chevalier Royal Observatory of Belgium, 3 Avenue Circulaire, 1180 Brussels, Belgium

e-mail: qbaire@oma.be 